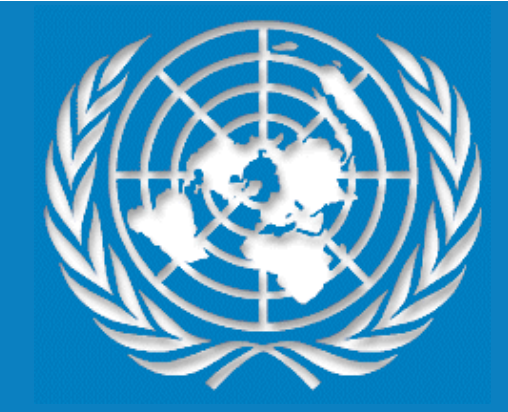

CONVENCIÓN DE LAS NACIONES UNIDAS CONTRA EL

TRÁFICO ILÍCITO DE ESTUPEFACIENTES Y

SUSTANCIAS SICOTRÓPICAS,

1988

NACIONES UNIDAS 
Convención de las Naciones Unidas contra el Tráfico Ilícito de

Estupefacientes y Sustancias Sicotrópicas

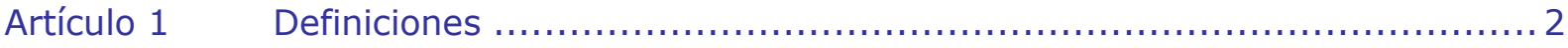

Artículo 2 Alcance de la presente Convención .......................................... 3

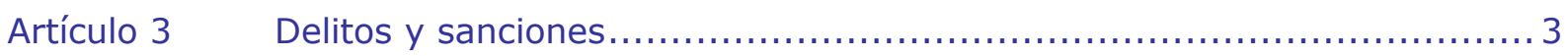

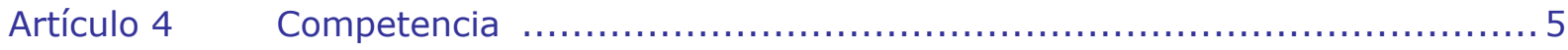

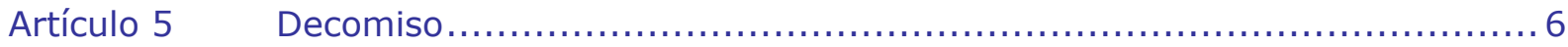

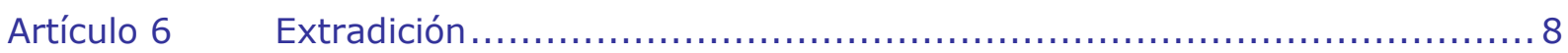

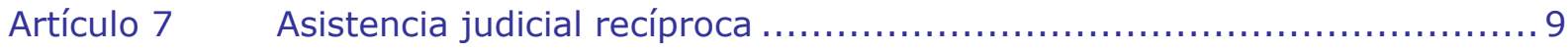

Artículo $8 \quad$ Remisión de actuaciones penales....................................... 11

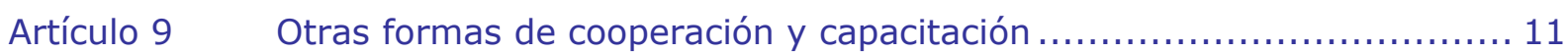

Artículo 10 Cooperación internacional y asistencia a los Estados de tránsito............12

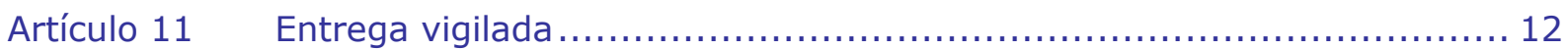

Artículo 12 Sustancias que se utilizan con frecuencia en la fabricación ilícita de estupefacientes o sustancias sicotrópicas............................... 12

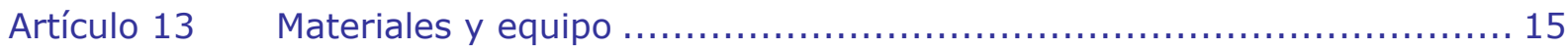

Artículo 14 Medidas para erradicar el cultivo ilícito de plantas de las que se extraen estupefacientes y para eliminar la demanda ilícita de estupefacientes y sustancias sicotrópicas...................................................... 15

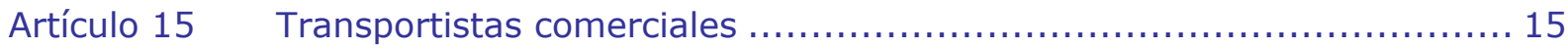

Artículo 16 Documentos comerciales y etiquetas de las exportaciones .................16

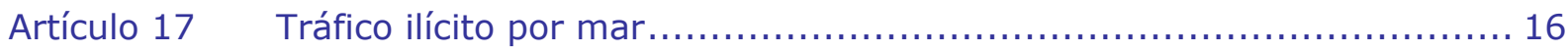

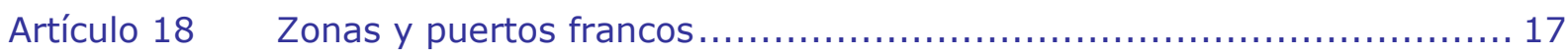

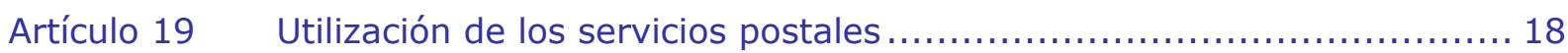

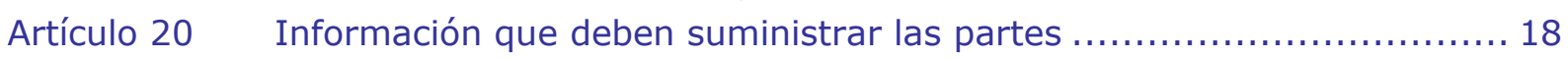

Artículo $21 \quad$ Funciones de la Comisión ............................................... 18

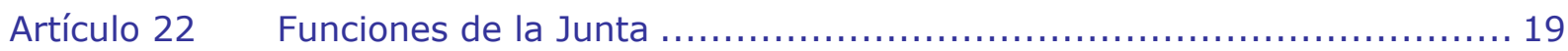

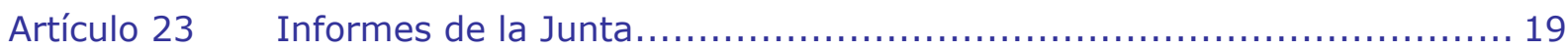

Artículo 24 Aplicación de medidas mas estrictas que las establecidas por la

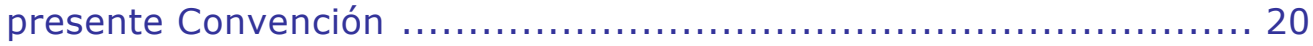

Artículo 25 Efecto no derogatorio respecto de anteriores derechos y obligaciones

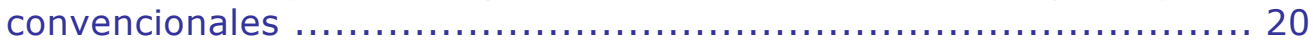

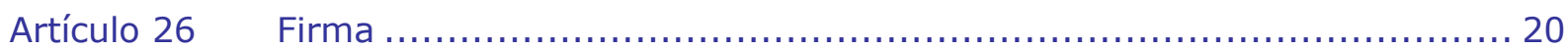

Artículo 27 Ratificación, aceptación, aprobación o acto de confirmación formal...... 20

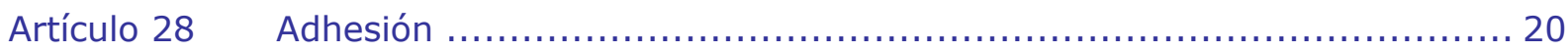

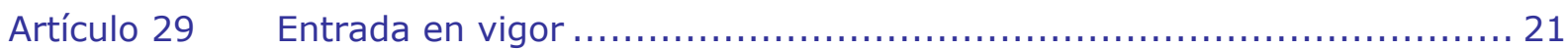



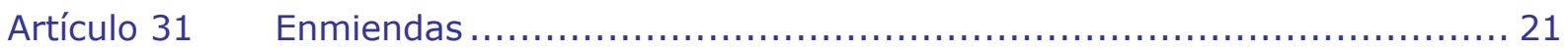

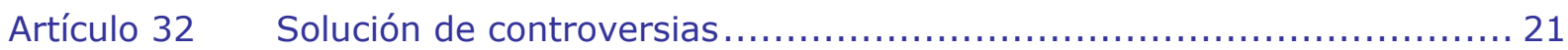

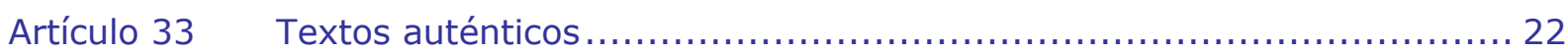

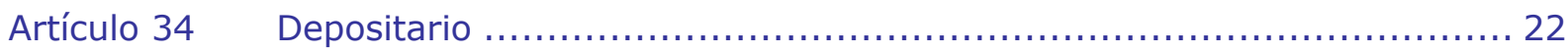




\section{Convención de las Naciones Unidas contra el Tráfico Ilícito de ESTUPEFACIENTES Y SUSTANCIAS SiCOTRÓPICAS}

\section{Las Partes en la presente Convención,}

Profundamente preocupadas por la magnitud y la tendencia creciente de la producción, la demanda y el tráfico ilícitos de estupefacientes y sustancias sicotrópicas, que representan una grave amenaza para la salud y el bienestar de los seres humanos y menoscaban las bases económicas, culturales y políticas de la sociedad,

Profundamente preocupadas asimismo por la sostenida y creciente penetración del tráfico ilícito de estupefacientes y sustancias sicotrópicas en los diversos grupos sociales y, particularmente, por la utilización de niños en muchas partes del mundo como mercado de consumo y como instrumentos para la producción, la distribución y el comercio ilícitos de estupefacientes y sustancias sicotrópicas, lo que entraña un peligro de gravedad incalculable,

Reconociendo los vínculos que existen entre el tráfico ilícito y otras actividades delictivas organizadas relacionadas con él, que socavan las economías lícitas y amenazan la estabilidad, la seguridad y la soberanía de los Estados,

Reconociendo también que el tráfico ilícito es una actividad delictiva internacional cuya supresión exige urgente atención y la más alta prioridad,

Conscientes de que el tráfico ilícito genera considerables rendimientos financieros y grandes fortunas que permiten a las organizaciones delictivas transnacionales invadir, contaminar y corromper las estructuras de la administración pública, las actividades comerciales y financieras lícitas y la sociedad a todos sus niveles,

Decididas a privar a las personas dedicadas al tráfico ilícito del producto de sus actividades delictivas y eliminar así su principal incentivo para tal actividad,

Deseosas de eliminar las causas profundas del problema del uso indebido de estupefacientes y sustancias sicotrópicas, comprendida la demanda ilícita de dichas drogas y sustancias y las enormes ganancias derivadas del tráfico ilícito,

Considerando que son necesarias medidas de control con respecto a determinadas sustancias, como los precursores, productos químicos y disolventes, que se utilizan en la fabricación de estupefacientes y sustancias sicotrópicas, y que, por la facilidad con que se consiguen, han provocado un aumento de la fabricación clandestina de esas drogas y sustancias,

Decididas a mejorar la cooperación internacional para la supresión del tráfico ilícito por mar,

Reconociendo que la erradicación del tráfico ilícito es responsabilidad colectiva de todos los Estados y que, a ese fin, es necesaria una acción coordinada en el marco de la cooperación internacional,

Reconociendo también la competencia de las Naciones Unidas en materia de fiscalización de estupefacientes y sustancias sicotrópicas y deseando que los órganos internacionales relacionados con esa fiscalización actúen dentro del marco de las Naciones Unidas,

Reafirmando los principios rectores de los tratados vigentes sobre fiscalización de estupefacientes y sustancias sicotrópicas y el sistema de fiscalización que establecen,

Reconociendo la necesidad de fortalecer y complementar las medidas previstas en la Convención Única de 1961 sobre Estupefacientes, en esa Convención enmendada por el Protocolo de 1972 de Modificación de la Convención Única de 1961 sobre Estupefacientes y en el Convenio sobre Sustancias Sicotrópicas de 1971, con el fin de enfrentarse a la magnitud y difusión del tráfico ilícito y sus graves consecuencias,

Reconociendo también la importancia de robustecer e intensificar medios jurídicos eficaces de cooperación internacional en asuntos penales para suprimir las actividades delictivas internacionales de tráfico ilícito, 
Deseosas de concertar una convención internacional que sea un instrumento completo, eficaz y operativo, específicamente dirigido contra el tráfico ilícito, en la que se tomen en cuenta los diversos aspectos del problema en su conjunto, en particular los que no estén previstos en los tratados vigentes en la esfera de los estupefacientes y sustancias sicotrópicas,

Convienen en lo siguiente:

\section{Artículo 1}

\section{DEFINICIONES}

Salvo indicación expresa en contrario, o que el contexto haga necesaria otra interpretación, las siguientes definiciones se aplicarán en todo el texto de la presente Convención:

a) Por "Junta" se entiende la Junta Internacional de Fiscalización de Estupefacientes establecida por la Convención Única de 1961 sobre Estupefacientes y en esa Convención enmendada por el Protocolo de 1972 de Estupefaciente de la Convención Única de 1961 sobre Estupefacientes;

b) Por "planta de cannabis" se entiende toda planta del género Cannabis;

c) Por "arbusto de coca" se entiende la planta de cualesquiera especies del género Erythroxylon;

d) Por "transportista comercial" se entiende una persona o una entidad publica, privada o de otro tipo dedicada al transporte de personas, bienes o correo a título oneroso.

e) Por "Comisión" se entiende la Comisión de Estupefacientes del Consejo Económico y Social de las Naciones Unidas;

f) Por "decomiso" se entiende la privación con carácter definitivo de algún bien por decisión de un tribunal o de otra autoridad competente;

g) Por "entrega vigilada" se entiende la técnica consistente en dejar que remesas ilícitas o sospechosas de estupefacientes, sustancias sicotrópicas, sustancias que figuran en el Cuadro I o el Cuadro II anexos a la presente Convención o sustancias por las que se hayan sustituido las anteriormente mencionadas, salgan del territorio de uno o mas países, lo atraviesen o entren en él, con el conocimiento y bajo la supervisión de sus autoridades competentes, con el fin de identificar a las personas involucradas en la comisión de delitos tipificados de conformidad con el párrafo 1 del artículo 3 de la presente Convención;

h) Por "Convención de 1961" se entiende la Convención Única de 1961 sobre Estupefacientes;

i) Por "Convención de 1961 en su forma enmendada" se entiende la Convención Única de 1961 sobre Estupefacientes enmendada por el Protocolo de 1972 de Modificación de la Convención Única de 1961 sobre Estupefacientes;

j) Por "Convenio de 1971" se entiende el Convenio sobre Sustancias Sicotrópicas de 1971;

k) Por "Consejo" se entiende el Consejo Económico y Social de las Naciones Unidas;

l) Por "embargo preventivo" o "incautación" se entiende la prohibición temporal de transferir, convertir, enajenar o mover bienes, o la custodia o el control temporales de bienes por mandamiento expedido por un tribunal o por una autoridad competente;

m) Por "tráfico ilícito" se entiende los delitos enunciados en los párrafos 1 y 2 del artículo 3 de la presente Convención;

n) Por "estupefaciente" se entiende cualquiera de las sustancias, naturales o sintéticas, que figuran en la Lista I o la Lista II de la Convención Única de 1961 sobre Estupefacientes y en esa Convención enmendada por el Protocolo de 1972 de Modificación de la Convención Única de 1961 sobre Estupefacientes;

o) Por "adormidera" se entiende la planta de la especie Papaver somniferum L;

p) Por "producto" se entiende los bienes obtenidos o derivados directa o indirectamente de la comisión de un delito tipificado de conformidad con el párrafo 1 del artículo 3;

q) Por "bienes" se entiende los activos de cualquier tipo, corporales o incorporales, muebles o raíces, tangibles o intangibles, y los documentos o instrumentos legales que acrediten la propiedad u otros derechos sobre dichos activos;

r) Por "sustancia sicotrópica" se entiende cualquier sustancia, natural o sintética, o cualquier material natural que figure en las Listas I, II, III O IV del Convenio sobre Sustancias Sicotrópicas de 1971;

s) Por "Secretario General" se entiende el Secretario General de las Naciones Unidas.

t) Por "Cuadro I" y "Cuadro II" se entiende la lista de sustancias que con esa numeración se anexa a la presente Convención, enmendada oportunamente de conformidad con el artículo 12; 
u) Por "Estado de tránsito" se entiende el Estado a través de cuyo territorio se hacen pasar estupefacientes, sustancias sicotrópicas y sustancias que figuran en el Cuadro I y el Cuadro II, de carácter ilícito, y que no es el punto de procedencia ni el de destino definitivo de esas sustancias.

\section{Artículo 2}

\section{AlCANCE DE LA PRESENTE CONVENCiÓN}

1. El propósito de la presente Convención es promover la cooperación entre las Partes a fin de que puedan hacer frente con mayor eficacia a los diversos aspectos del tráfico ilícito de estupefacientes y sustancias sicotrópicas que tengan una dimensión internacional. En el cumplimiento de las obligaciones que hayan contraído en virtud de la presente Convención, las Partes adoptarán las medidas necesarias, comprendidas las de orden legislativo y administrativo, de conformidad con las disposiciones fundamentales de sus respectivos ordenamientos jurídicos internos.

2. Las Partes cumplirán sus obligaciones derivadas de la presente Convención de manera que concuerde con los principios de la igualdad soberana y de la integridad territorial de los Estados y de la no intervención en los asuntos internos de otros Estados.

3. Una Parte no ejercerá en el territorio de otra Parte competencias ni funciones que hayan sido reservadas exclusivamente a las autoridades de esa otra Parte por su derecho interno.

\section{Artículo 3}

\section{DELITOS Y SANCIONES}

1. Cada una de las Partes adoptará las medidas que sean necesarias para tipificar como delitos penales en su derecho interno, cuando se cometan intencionalmente:

a) i) La producción, la fabricación, la extracción, la preparación, la oferta, la oferta para la venta, la distribución, la venta, la entrega en cualesquiera condiciones, el corretaje, el envío, el envío en tránsito, el transporte, la importación o la exportación de cualquier estupefaciente o sustancia sicotrópica en contra de lo dispuesto en la Convención de 1961, en la Convención de 1961 en su forma enmendada o en el Convenio de 1971;

ii) El cultivo de la adormidera, el arbusto de coca o la planta de cannabis con objeto de producir estupefacientes en contra de lo dispuesto en la Convención de 1961 y en la Convención de 1961 en su forma enmendada;

iii) La posesión o la adquisición de cualquier estupefaciente o sustancia sicotrópica con objeto de realizar cualquiera de las actividades enumeradas en el precedente apartado i);

iv) La fabricación, el transporte o la distribución de equipos, materiales o de las sustancias enumeradas en el Cuadro I y el Cuadro II, a sabiendas de que van a utilizarse en el cultivo, la producción o la fabricación ilícitos de estupefacientes o sustancias sicotrópicas o para dichos fines;

v) La organización, la gestión o la financiación de alguno de los delitos enumerados en los precedentes apartados i), ii), iii) o iv);

b) i) La conversión o la transferencia de bienes a sabiendas de que tales bienes proceden de alguno o algunos de los delitos tipificados de conformidad con el inciso a) del presente párrafo, o de un acto de participación en tal delito o delitos, con objeto de ocultar o encubrir el origen ilícito de los bienes o de ayudar a cualquier persona que participe en la comisión de tal delito o delitos a eludir las consecuencias jurídicas de sus acciones;

ii) La ocultación o el encubrimiento de la naturaleza, el origen, la ubicación, el destino, el movimiento o la propiedad reales de bienes, o de derechos relativos a tales bienes, a sabiendas de que proceden de alguno o algunos de los delitos tipificados de conformidad con el inciso a) del presente párrafo o de un acto de participación en tal delito o delitos; 
c) A reserva de sus principios constitucionales y de los conceptos fundamentales de su ordenamiento jurídico:

i) La adquisición, la posesión o la utilización de bienes, a sabiendas, en el momento de recibirlos, de que tales bienes proceden de alguno o algunos de los delitos tipificados de conformidad con el inciso a) del presente párrafo o de un acto de participación en tal delito o delitos;

ii) La posesión de equipos o materiales o sustancias enumeradas en el Cuadro I y el Cuadro II, a sabiendas de que se utilizan o se habrán de utilizar en el cultivo, la producción o la fabricación ilícitos de estupefacientes o sustancias sicotrópicas o para tales fines;

iii) Instigar o inducir públicamente a otros, por cualquier medio, a cometer alguno de los delitos tipificados de conformidad con el presente artículo o a utilizar ilícitamente estupefacientes o sustancias sicotrópicas;

iv) La participación en la comisión de alguno de los delitos tipificados de conformidad con lo dispuesto en el presente artículo, la asociación y la confabulación para cometerlos, la tentativa de cometerlos, y la asistencia, la incitación, la facilitación o el asesoramiento en relación con su comisión.

2. A reserva de sus principios constitucionales y de los conceptos fundamentales de su ordenamiento jurídico, cada una de las Partes adoptará las medidas que sean necesarias para tipificar como delitos penales conforme a su derecho interno, cuando se cometan intencionalmente, la posesión, la adquisición o el cultivo de estupefacientes o sustancias sicotrópicas para el consumo personal en contra de lo dispuesto en la Convención de 1961, en la Convención de 1961 en su forma enmendada o en el Convenio de 1971.

3. El conocimiento, la intención o la finalidad requeridos como elementos de cualquiera de los delitos enunciados en el párrafo 1 del presente artículo podrán inferirse de las circunstancias objetivas del caso.

4. a) Cada una de las Partes dispondrá que por la comisión de los delitos tipificados de conformidad con el párrafo 1 del presente artículo se apliquen sanciones proporcionadas a la gravedad de esos delitos, tales como la pena de prisión u otras formas de privación de libertad, las sanciones pecuniarias y el decomiso.

b) Las Partes podrán disponer, en los casos de delitos tipificados de conformidad con el párrafo 1 del presente artículo, que, como complemento de la declaración de culpabilidad o de la condena, el delincuente sea sometido a medidas de tratamiento, educación, postratamiento, rehabilitación o reinserción social.

c) No obstante lo dispuesto en los incisos anteriores, en los casos apropiados de infracciones de carácter leve, las Partes podrán sustituir la declaración de culpabilidad o la condena por la aplicación de otras medidas tales como las de educación, rehabilitación o reinserción social, así como, cuando el delincuente sea un toxicómano, de tratamiento y postratamiento.

d) Las Partes podrán, ya sea a título sustitutivo de la declaración de culpabilidad o de la condena por un delito tipificado de conformidad con el párrafo 2 del presente artículo o como complemento de dicha declaración de culpabilidad o de dicha condena, disponer medidas de tratamiento, educación, postratamiento, rehabilitación o reinserción social del delincuente.

5. Las Partes dispondrán lo necesario para que sus tribunales y demás autoridades jurisdiccionales competentes puedan tener en cuenta las circunstancias de hecho que den particular gravedad a la comisión de los delitos tipificados de conformidad con el párrafo I, del presente artículo, tales como:

a) La participación en el delito de un grupo delictivo organizado del que el delincuente forme parte;

b) La participación del delincuente en otras actividades delictivas internacionales organizadas;

c) La participación del delincuente en otras actividades ilícitas cuya ejecución se vea facilitada por la comisión del delito;

d) El recurso a la violencia o el empleo de armas por parte del delincuente;

e) El hecho de que el delincuente ocupe un cargo público y de que el delito guarde relación con ese cargo;

f) La victimización o utilización de menores de edad;

g) El hecho de que el delito se haya cometido en establecimientos penitenciarios, en una institución educativa o en un centro asistencial o en sus inmediaciones o en otros lugares a los que escolares y estudiantes acudan para realizar actividades educativas, deportivas y sociales; 
h) Una declaración de culpabilidad anterior, en particular por delitos análogos, por tribunales extranjeros o del propio país, en la medida en que el derecho interno de cada una de las Partes lo permita.

6. Las Partes se esforzarán por asegurarse de que cualesquiera facultades legales discrecionales, conforme a su derecho interno, relativas al enjuiciamiento de personas por los delitos tipificados de conformidad con lo dispuesto en el presente artículo, se ejerzan para dar la máxima eficacia a las medidas de detección y represión, respecto de esos delitos teniendo debidamente en cuenta la necesidad de ejercer un efecto disuasivo en lo referente a la comisión de esos delitos.

7. Las Partes velarán porque sus tribunales o demás autoridades competentes tengan en cuenta la gravedad de los delitos enumerados en el párrafo 1 del presente artículo y las circunstancias enumeradas en el párrafo 5 del presente artículo al considerar la posibilidad de conceder la libertad anticipada o la libertad condicional a personas que hayan sido declaradas culpables de alguno de esos delitos.

8. Cada una de las Partes establecerá, cuando proceda, en su derecho interno un plazo de prescripción prolongado dentro del cual se pueda iniciar el procesamiento por cualquiera de los delitos tipificados de conformidad con el párrafo 1 del presente artículo. Dicho plazo será mayor cuando el presunto delincuente hubiese eludido la administración de justicia.

9. Cada una de las Partes adoptará medidas adecuadas, conforme a lo previsto en su propio ordenamiento jurídico, para que la persona que haya sido acusada o declarada culpable de alguno de los delitos tipificados de conformidad con el párrafo 1 del presente artículo, que se encuentre en el territorio de dicha Parte, comparezca en el proceso penal correspondiente.

10. A los fines de la cooperación entre las Partes prevista en la presente Convención, en particular la cooperación prevista en los artículos 5, 6, 7 y 9, los delitos tipificados de conformidad con el presente artículo no se considerarán como delitos fiscales o como delitos políticos ni como delitos políticamente motivados, sin perjuicio de las limitaciones constitucionales y de los principios fundamentales del derecho interno de las Partes.

11. Ninguna de las disposiciones del presente artículo afectará al principio de que la tipificación de los delitos a que se refiere o de las excepciones alegables en relación con estos queda reservada al derecho interno de las Partes y de que esos delitos han de ser enjuiciados y sancionados con arreglo a lo previsto en ese derecho.

\section{Artículo 4}

\section{COMPETENCIA}

1. Cada una de las Partes:

a) Adoptará las medidas que sean necesarias para declararse competente respecto de los delitos que haya tipificado de conformidad con el párrafo I del artículo 3:

i) Cuando el delito se cometa en su territorio;

ii) Cuando el delito se cometa a bordo de una nave que enarbole su pabellón o de una aeronave matriculada con arreglo a su legislación en el momento de cometerse el delito;

b) Podrá adoptar las medidas que sean necesarias para declararse competente respecto de los delitos que haya tipificado de conformidad con el párrafo 1 del artículo 3:

i) Cuando el delito sea cometido por un nacional suyo o por una persona que tenga su residencia habitual en su territorio;

ii) Cuando el delito se cometa a bordo de una nave para cuya incautación dicha Parte haya recibido previamente autorización con arreglo a lo previsto en el artículo 17, siempre que esa competencia se ejerza únicamente sobre la base de los acuerdos o arreglos a que se hace referencia en los párrafos 4 y 9 de dicho artículo;

iii) Cuando el delito sea uno de los tipificados de conformidad con el apartado iv) del inciso c) del párrafo 1 del artículo 3 y se cometa fuera de su territorio con miras a perpetrar en él uno de los delitos tipificados de conformidad con el párrafo 1 del artículo 3. 
2. Cada una de las Partes:

a) Adoptará también las medidas que sean necesarias para declararse competente respecto de los delitos que haya tipificado de conformidad con el párrafo 1 del artículo 3, cuando el presunto delincuente se encuentre en su territorio y dicha Parte no lo extradite a otra basándose en que:

i) El delito se ha cometido en su territorio o a bordo de una nave que enarbole su pabellón o de una aeronave matriculada con arreglo a su legislación en el momento de cometerse el delito; o

ii) El delito ha sido cometido por un nacional suyo;

b) Podrá adoptar también las medidas que sean necesarias para declararse competente respecto de los delitos que haya tipificado de conformidad con el párrafo 1 del artículo 3, cuando el presunto delincuente se encuentre en su territorio y dicha Parte no lo extradite a otra.

3. La presente Convención no excluye el ejercicio de las competencias penales establecidas por una Parte de conformidad con su derecho interno.

Artículo 5

\section{DECOMISO}

1. Cada una de las Partes adoptará las medidas que sean necesarias para autorizar el decomiso:

a) Del producto derivado de delitos tipificados de conformidad con el párrafo 1 del artículo 3, o de bienes cuyo valor equivalga al de ese producto;

b) De estupefacientes y sustancias sicotrópicas, los materiales y equipos u otros instrumentos utilizados o destinados a ser utilizados en cualquier forma para cometer los delitos tipificados de conformidad con el párrafo 1 del articulo 3.

2. Cada una de las Partes adoptará también las medidas que sean necesarias para permitir a sus autoridades competentes la identificación, la detección y el embargo preventivo o la incautación del producto, los bienes, los instrumentos o cualesquiera otros elementos a que se refiere el párrafo 1 del presente artículo, con miras a su eventual decomiso.

3. A fin de dar aplicación a las medidas mencionadas en el presente artículo, cada una de las Partes facultará a sus tribunales u otras autoridades competentes a ordenar la presentación o la incautación de documentos bancarios, financieros o comerciales. Las Partes no podrán negarse a aplicar las disposiciones del presente párrafo amparándose en el secreto bancario.

4. a) Al recibirse una solicitud formulada con arreglo al presente artículo por otra Parte que sea competente respecto de un delito tipificado de conformidad con el párrafo 1 del articulo 3, la Parte en cuyo territorio se encuentren el producto, los bienes, los instrumentos o cualesquiera otros de los elementos a que se refiere el párrafo 1 del presente artículo:

i) Presentará la solicitud a sus autoridades competentes con el fin de obtener un mandamiento de decomiso al que, en caso de concederse, dará cumplimiento; o

ii) Presentará ante sus autoridades competentes, a fin de que se le dé cumplimiento en la medida solicitada, el mandamiento de decomiso expedido por la Parte requirente de conformidad con el párrafo I del presente artículo, en lo que se refiera al producto, los bienes, los instrumentos o cualesquiera otros elementos a que se refiere el párrafo 1 que se encuentren en el territorio de la Parte requerida.

b) Al recibirse una solicitud formulada con arreglo al presente artículo por otra Parte que sea competente por respecto de un delito tipificado de conformidad con el párrafo 1 del artículo 3, la Parte requerida adoptará medidas para la identificación, la detección y el embargo preventivo o la incautación del producto, los bienes, los instrumentos o cualesquiera otros elementos a que se refiere el párrafo 1 del presente artículo, con miras al eventual decomiso que se ordene, ya sea por la Parte requirente o, cuando se haya formulado una solicitud con arreglo al inciso a) del presente párrafo, por la Parte requerida. 
c) Las decisiones o medidas previstas en los incisos a) y b) del presente párrafo serán adoptadas por la Parte requerida de conformidad con su derecho interno y con sujeción a sus disposiciones, y de conformidad con sus reglas de procedimiento o los tratados, acuerdos o arreglos bilaterales o multilaterales que haya concertado con la Parte requirente.

d) Será aplicable, mutatis mutandis, lo dispuesto en los párrafos 6 a 19 del artículo 7. Además de la información enumerada en el párrafo 10 del artículo 7, las solicitudes formuladas de conformidad con el presente artículo contendrán lo siguiente:

i) En el caso de una solicitud correspondiente al apartado i) del inciso a) del presente párrafo, una descripción de los bienes por decomisar y una exposición de los hechos en que se funde la Parte requirente que sea suficiente para que la Parte requerida pueda tramitar el mandamiento con arreglo a su derecho interno;

ii) En el caso de una solicitud correspondiente al apartado ii) del inciso a), una copia admisible en derecho de un mandamiento de decomiso expedido por la Parte requirente que sirva de fundamento a la solicitud, una exposición de los hechos e información sobre el alcance de la solicitud de ejecución del mandamiento;

iii) En el caso de una solicitud correspondiente al inciso b), una exposición de los hechos en que se funde la Parte requirente y una descripción de las medidas solicitadas.

e) Cada una de las Partes proporcionará al Secretario General el texto de cualesquiera de sus leyes y reglamentos por los que haya dado aplicación al presente párrafo, así como el texto de cualquier cambio ulterior que se efectúe en dichas leyes y reglamentos.

f) Si una de las Partes opta por supeditar la adopción de las medidas mencionadas en los incisos a) y b) del presente párrafo a la existencia de un tratado pertinente, dicha Parte considerará la presente Convención como base convencional necesaria y suficiente.

g) Las Partes procurarán concertar tratados, acuerdos o arreglos bilaterales y multilaterales para mejorar la eficacia de la cooperación internacional prevista en el presente artículo.

5. a) La Parte que haya decomisado el producto o los bienes conforme a los párrafos 1 ó 4 del presente artículo dispondrá de ellos en la forma prevista por su derecho interno y sus procedimientos administrativos.

b) Al actuar a solicitud de otra Parte, con arreglo a lo previsto en el presente artículo, la Parte podrá prestar particular atención a la posibilidad de concertar acuerdos a fin de:

i) Aportar la totalidad o una parte considerable del valor de dicho producto y de dichos bienes, o de los costos derivados de la venta de dicho producto o de dichos bienes, a organismos intergubernamentales especializados en la lucha contra el tráfico ilícito y el uso indebido de estupefacientes y sustancias sicotrópicas;

ii) Repartirse con otras Partes, conforme a un criterio preestablecido o definido para cada caso, dicho producto o dichos bienes, o los costos derivados de la venta de dicho producto o de dichos bienes, con arreglo a lo previsto por su derecho interno, sus procedimientos administrativos o los acuerdos bilaterales o multilaterales que hayan concertado a este fin.

6. a) Cuando el producto se haya transformado o convertido en otros bienes, estos podrán ser objeto de las medidas aplicables al producto mencionadas en el presente artículo.

b) Cuando el producto se haya mezclado con bienes adquiridos de fuentes lícitas, sin perjuicio de cualquier otra facultad de incautación o embargo preventivo aplicable, se podrán decomisar dichos bienes hasta el valor estimado del producto mezclado.

c) Dichas medidas se aplicarán asimismo a los ingresos u otros beneficios derivados:

i) Del producto;

ii) De los bienes con los cuales el producto haya sido transformado o convertido; o

iii) De los bienes con los cuales se haya mezclado el producto de la misma manera y en la misma medida que al producto.

7. Cada una de las Partes considerará la posibilidad de invertir la carga de la prueba respecto del origen lícito del supuesto producto u otros bienes sujetos a decomiso, en la medida en que ello sea compatible con los principios de su derecho interno y con la naturaleza de sus procedimientos judiciales y de otros procedimientos. 
8. Lo dispuesto en el presente artículo no podrá interpretarse en perjuicio de los derechos de terceros de buena fe.

9. Nada de lo dispuesto en el presente artículo afectará al principio de que las medidas que en él se prevén serán definidas y aplicadas de conformidad con el derecho interno de cada una de las Partes, y con arreglo a lo dispuesto en él.

\section{Artículo 6}

\section{EXTRADICIÓN}

1. El presente artículo se aplicará a los delitos tipificados por las Partes de conformidad con el párrafo 1 del artículo 3.

2. Cada uno de los delitos a los que se aplica el presente artículo se considerará incluido entre los delitos que den lugar a extradición en todo tratado de extradición vigente entre las Partes. Las Partes se comprometen a incluir tales delitos como casos de extradición en todo tratado de extradición que concierten entre sí.

3. Si una Parte que supedita la extradición a la existencia de un tratado recibe de otra Parte, con la que no la vincula ningún tratado de extradición, una solicitud de extradición, podrá considerar la presente Convención como la base jurídica de la extradición respecto de los delitos a los que se aplica el presente artículo. Las Partes que requieran una legislación detallada para hacer valer la presente Convención como base jurídica de la extradición considerarán la posibilidad de promulgar la legislación necesaria.

4. Las Partes que no supediten la extradición a la existencia de un tratado reconocerán los delitos a los que se aplica el presente artículo como casos de extradición entre ellas.

5. La extradición estará sujeta a las condiciones previstas por la legislación de la Parte requerida o por los tratados de extradición aplicables, incluidos los motivos por los que la Parte requerida puede denegar la extradición.

6. Al examinar las solicitudes recibidas de conformidad con el presente artículo, el Estado requerido podrá negarse a darles cumplimiento cuando existan motivos justificados que induzcan a sus autoridades judiciales u otras autoridades competentes a presumir que su cumplimiento facilitará el procesamiento o el castigo de una persona por razón de su raza, religión, nacionalidad u opiniones políticas o que se ocasionarán perjuicios por alguna de estas razones a alguna persona afectada por la solicitud.

7. Las Partes se esforzarán por agilizar los procedimientos de extradición y simplificar los requisitos probatorios con respecto a cualquiera de los delitos a los que se aplica el presente artículo.

8. A reserva de lo dispuesto en su derecho interno y en sus tratados de extradición, la Parte requerida podrá, tras haberse cerciorado de que las circunstancias lo justifican y tienen carácter urgente, y a solicitud de la Parte requirente, proceder a la detención de la persona cuya extradición se solicite y que se encuentre en su territorio o adoptar otras medidas adecuadas para asegurar su comparecencia en los trámites de extradición.

9. Sin perjuicio del ejercicio de cualquier competencia penal declarada de conformidad con su derecho interno, la Parte en cuyo territorio se encuentre un presunto delincuente deberá:

a) Si no lo extradita por un delito tipificado de conformidad con el párrafo I del artículo 3 por los motivos enunciados en el inciso a) del párrafo 2 del artículo 4, presentar el caso ante sus autoridades competentes para enjuiciarlo, salvo que se haya acordado otra cosa con la Parte requirente;

b) Si no lo extradita por un delito de ese tipo y se ha declarado competente en relación con ese delito de conformidad con el inciso b) del párrafo 2 del artículo 4, presentar el caso ante sus autoridades competentes para enjuiciarlo, salvo que la Parte requirente solicite otra coca a efectos de salvaguardar su competencia legítima.

10. Si la extradición solicitada con el propósito de que se cumpla una condena se deniega basándose en que la persona objeto de la solicitud es nacional de la Parte requerida, ésta, si su legislación lo permite y de conformidad con los requisitos de dicha legislación, previa solicitud de la Parte requirente, considerará la posibilidad de hacer cumplir la condena impuesta conforme a la legislación de la Parte requirente o el resto de dicha condena que quede por purgar. 
11. Las Partes procurarán concertar acuerdos bilaterales y multilaterales para llevar a cabo la extradición o aumentar su eficacia.

12. Las Partes podrán considerar la posibilidad de concertar acuerdos bilaterales o multilaterales, ya sean especiales o generales, sobre el traslado de las personas condenadas a prisión u otra forma de privación de libertad por los delitos a los que se aplica el presente artículo, a fin de que puedan terminar de cumplir sus condenas en su país.

\section{Artículo 7}

\section{ASISTENCIA JUDICIAL RECÍPROCA}

1. Las Partes se prestarán, a tenor de lo dispuesto en el presente artículo, la más amplia asistencia judicial recíproca en las investigaciones, procesos y actuaciones judiciales referentes a delitos tipificados de conformidad con el párrafo 1 del artículo 3.

2. La asistencia judicial recíproca que ha de prestarse de conformidad con el presente artículo podrá ser solicitada para cualquiera de los siguientes fines:

a) Recibir testimonios o tomar declaración a personas;

b) Presentar documentos judiciales;

c) Efectuar inspecciones e incautaciones;

d) Examinar objetos y lugares;

e) Facilitar información y elementos de prueba;

f) Entregar originales o copias autenticas de documentos y expedientes relacionados con

el caso, inclusive documentación bancaria, financiera, social y comercial;

g) Identificar o detectar el producto, los bienes, los instrumentos u otros elementos con fines probatorios.

3. Las Partes podrán prestarse cualquier otra forma de asistencia judicial recíproca autorizada por el derecho interno de la Parte requerida.

4. Las Partes, si así se les solicita y en la medida compatible con su derecho y práctica internos, facilitarán o alentarán la presentación o disponibilidad de personas, incluso de detenidos, que consientan en colaborar en las investigaciones o en intervenir en las actuaciones.

5. Las Partes no invocarán el secreto bancario para negarse a prestar asistencia judicial recíproca con arreglo al presente artículo.

6. Lo dispuesto en el presente artículo no afectará a las obligaciones derivadas de otros tratados bilaterales o multilaterales, vigentes o futuros, que rijan, total o parcialmente la asistencia judicial recíproca en asuntos penales.

7. Los párrafos 8 a 19 del presente artículo se aplicarán a las solicitudes que se formulen con arreglo al mismo, siempre que no medie entre las Partes interesadas un tratado de asistencia judicial recíproca. Cuando las Partes estén vinculadas por un tratado de esta índole, se aplicarán las disposiciones correspondientes de dicho tratado, salvo que las Partes convengan en aplicar, en su lugar, los párrafos 8 a 19 del presente artículo.

8. Las Partes designarán una autoridad o, cuando sea necesario, varias autoridades, con facultades para dar cumplimiento a las solicitudes de asistencia judicial recíproca o transmitirlas a las autoridades competentes para su ejecución. Se notificará al Secretario General la autoridad o autoridades que hayan sido designadas para este fin. Las autoridades designadas por las Partes serán las encargadas de transmitir las solicitudes de asistencia judicial recíproca y cualquier otra comunicación pertinente; la presente disposición no afectará al derecho de cualquiera de las Partes a exigir que estas solicitudes y comunicaciones le sean enviadas por vía diplomática y, en circunstancias urgentes, cuando las Partes convengan en ello, por conducto de la Organización Internacional de Policía Criminal, de ser ello posible.

9. Las solicitudes deberán presentarse por escrito en un idioma aceptable para la Parte requerida. Se notificará al Secretario General el idioma o idiomas que sean aceptables para cada una de las Partes. En situaciones de urgencia, y cuando las Partes convengan en ello se podrán hacer las solicitudes verbalmente, debiendo ser seguidamente confirmadas por escrito. 
10. En las solicitudes de asistencia judicial recíproca deberá figurar lo siguiente:

a) La identidad de la autoridad que haga la solicitud;

b) El objeto y la índole de la investigación, del proceso o de las actuaciones a que se refiera la solicitud, y el nombre y funciones de la autoridad que esté efectuando dicha investigación, dicho procesamiento o dichas actuaciones;

c) Un resumen de los datos pertinentes, salvo cuando se trace de solicitudes para la presentación de documentos judiciales;

d) Una descripción de la asistencia solicitada y pormenores sobre cualquier procedimiento particular que la Parte requirente desee que se aplique;

e) Cuando sea posible, la identidad y la nacionalidad de toda persona involucrada y el lugar en que se encuentre;

f) La finalidad para la que se solicita la prueba, información o actuación.

11. La Parte requerida podrá pedir información adicional cuando sea necesaria para dar cumplimiento a la solicitud de conformidad con su derecho interno o para facilitar dicho cumplimiento.

12. Se dará cumplimiento a toda solicitud con arreglo al derecho interno de la Parte requerida y, en la medida en que no se contravenga la legislación de dicha Parte y siempre que ello sea posible, de conformidad con los procedimientos especificados en la solicitud.

13. La Parte requirente no comunicará ni utilizará, sin previo consentimiento de la Parte requerida, la información, o las pruebas proporcionadas por la Parte requerida para otras investigaciones, procesos o actuaciones distintas de las indicadas en la solicitud.

14. La Parte requirente podrá exigir que la Parte requerida mantenga reserva acerca de la existencia y el contenido de la solicitud, salvo en la medida necesaria para darle cumplimiento. Si la Parte requerida no puede mantener esa reserva, lo hará saber de inmediato a la Parte requirente.

15. La asistencia judicial recíproca solicitada podrá ser denegada:

a) Cuando la solicitud no se ajuste a lo dispuesto en el presente artículo;

b) Cuando la Parte requerida considere que el cumplimiento de lo solicitado pudiera menoscabar su soberanía, su seguridad, su orden público u otros intereses fundamentales;

c) Cuando el derecho interno de la Parte requerida prohíba a sus autoridades acceder a una solicitud formulada en relación con un delito análogo, si éste hubiera sido objeto de investigación, procesamiento o actuaciones en el ejercicio de su propia competencia;

d) Cuando acceder a la solicitud sea contrario al ordenamiento jurídico de la Parte requerida en lo relativo a la asistencia judicial recíproca.

16. Las denegaciones de asistencia judicial recíproca serán motivadas.

17. La asistencia judicial recíproca podrá ser diferida por la Parte requerida si perturbase el curso de una investigación, un proceso o unas actuaciones. En tal caso, la Parte requerida deberá consultar con la Parte requirente para determinar si es aun posible prestar la asistencia en la forma y en las condiciones que la primera estime necesarias.

18. El testigo, perito u otra persona que consienta en deponer en juicio o en colaborar en una investigación, proceso o actuación judicial en el territorio de la Parte requirente, no será objeto de procesamiento, detención o castigo, ni de ningún tipo de restricción de su libertad personal en dicho territorio por actos, omisiones o por declaraciones de culpabilidad anteriores a la fecha en que abandonó el territorio de la Parte requerida. Ese salvoconducto cesará cuando el testigo, perito u otra persona haya tenido durante 15 días consecutivos, o durante el período acordado por las Partes, después de la fecha en que se le haya informado oficialmente de que las autoridades judiciales ya no requerían su presencia, la oportunidad de salir del país y, no obstante, permanezca voluntariamente en el territorio o regrese espontáneamente a él después de haberlo abandonado.

19. Los gastos ordinarios que ocasione la ejecución de una solicitud serán sufragados por la Parte requerida salvo que las Partes interesadas hayan acordado otra cosa. Cuando se requieran a este fin gastos cuantiosos o de carácter extraordinario, las Partes se consultarán para determinar los términos y condiciones en que se haya de dar cumplimiento a la solicitud, así como la manera en que se sufragarán los gastos.

20. Cuando sea necesario, las Partes considerarán la posibilidad de concertar acuerdos o arreglos bilaterales o multilaterales que sirvan a los fines del presente artículo y que, en la práctica, den efecto a sus disposiciones o las refuercen. 


\section{REMISIÓN DE ACTUACIONES PENALES}

Las Partes considerarán la posibilidad de remitirse actuaciones penales para el procesamiento por los delitos tipificados de conformidad con el párrafo 1 del artículo 3, cuando se estime que esa remisión obrará en interés de una correcta administración de justicia.

\section{Artículo 9}

\section{OTRAS FORMAS DE COOPERACIÓN Y CAPACITACIÓN}

1. Las Partes colaborarán estrechamente entre sí, en armonía con sus respectivos ordenamientos jurídicos y administrativos, con miras a aumentar la eficacia de las medidas de detección y represión orientadas a suprimir la comisión de los delitos tipificados de conformidad con el párrafo 1 del artículo 3. Deberán, en particular, sobre la base de acuerdos o arreglos bilaterales o multilaterales:

a) Establecer y mantener canales de comunicación entre sus organismos y servicios competentes a fin de facilitar el intercambio rápido y seguro de información sobre todos los aspectos de los delitos tipificados de conformidad con el párrafo 1 del artículo 3, incluso, siempre que las Partes interesadas lo estimen oportuno, sobre sus vinculaciones con otras actividades delictivas;

b) Cooperar en la realización de indagaciones, con respecto a delitos tipificados de conformidad con el párrafo 1 del artículo 3 y de carácter internacional, acerca:

i) De la identidad, el paradero y las actividades de personas presuntamente implicadas en delitos tipificados de conformidad con el párrafo 1 del artículo 3;

ii) Del movimiento del producto o de los bienes destinados de la comisión de esos delitos;

iii) Del movimiento de estupefacientes, sustancias sicotrópicas, sustancias que figuran en el Cuando I y el Cuadro II de la presente Convención e instrumentos utilizados o destinados a ser utilizados en la comisión de esos delitos;

c) Cuando sea oportuno, y siempre que no contravenga lo dispuesto en su derecho interno, crear equipos conjuntos, teniendo en cuenta la necesidad de proteger la seguridad de las personas y de las operaciones, para dar efecto a lo dispuesto en el presente párrafo. Los funcionarios de cualquiera de las Partes que integren esos equipos actuarán conforme a la autorización de las autoridades competentes de la Parte en cuyo territorio se ha de llevar a cabo la operación. En todos esos casos las Partes de que se trate velarán porque se respete plenamente la soberanía de la Parte en cuyo territorio se ha de realizar la operación;

d) Proporcionar, cuando corresponda, las cantidades necesarias de sustancias para su análisis o investigación;

e) Facilitar una coordinación eficaz entre sus organismos y servicios competentes y promover el intercambio de personal y de otros expertos, incluso destacando funcionarios de enlace.

2. Cada una de las Partes, en la medida necesaria, iniciará, desarrollará o perfeccionará programas específicos de capacitación destinados a su personal de detección y represión o de otra índole, incluido el personal aduanero, encargado de suprimir los delitos tipificados de conformidad con el párrafo 1 del artículo 3. En particular, estos programas se referirán a:

a) Los métodos utilizados en la detección y supresión de los delitos tipificados de conformidad con el párrafo 1 del artículo 3;

b) Las rutas y técnicas utilizadas por personas presuntamente implicadas en delitos tipificados de conformidad con el párrafo 1 del artículo 3, en particular en los Estados de tránsito, y medidas adecuadas para contrarrestar su utilización;

c) La vigilancia de la importación y exportación de estupefacientes, sustancias sicotrópicas y sustancias que figuran en el Cuadro I y el Cuadro II;

d) La detección y vigilancia del movimiento del producto y los bienes derivados de la comisión de los delitos tipificados de conformidad con el párrafo 1 del artículo 3, y de los estupefacientes, sustancias sicotrópicas y sustancias que figuran en el Cuadro I y el Cuadro II, y de los instrumentos que se utilicen o se pretenda utilizar en la comisión de dichos delitos;

e) Los métodos utilizados para la transferencia, la ocultación o el encubrimiento de dicho producto, y de dichos bienes e instrumentos; 
f) El acopio de pruebas;

g) Las técnicas de fiscalización en zonas y puertos francos;

h) Las técnicas modernas de detección y represión.

3. Las Partes se prestarán asistencia en la planificación y ejecución de programas de investigación y capacitación encaminados a intercambiar conocimientos en las esferas mencionadas en el párrafo 2 del presente artículo y, a ese fin, deberán también, cuando proceda, recurrir a conferencias y seminarios regionales e internacionales a fin de promover la cooperación y estimular el examen de los problemas de interés común, incluidos en particular los problemas y necesidades especiales de los Estados de tránsito.

\section{Artículo 10}

\section{COOPERACIÓN INTERNACIONAL Y ASISTENCIA A LOS ESTADOS DE TRÁNSITO}

1. Las Partes cooperarán, directamente o por conducto de las organizaciones internacionales o regionales competentes, para prestar asistencia y apoyo a los Estados de tránsito y, en particular, a los países en desarrollo que necesiten de tales asistencia y apoyo, en la medida de lo posible, mediante programas de cooperación técnica para impedir la entrada y el tránsito ilícitos, así como para otras actividades conexas.

2. Las Partes podrán convenir, directamente o por conducto de las organizaciones internacionales o regionales competentes, en proporcionar asistencia financiera a dichos Estados de tránsito con el fin de aumentar y fortalecer la infraestructura que necesiten para una fiscalización y una prevención eficaces del tráfico ilícito.

3. Las Partes podrán concertar acuerdos o arreglos bilaterales o multilaterales para aumentar la eficacia de la cooperación internacional prevista en el presente artículo y podrán tomar en consideración la posibilidad de concertar arreglos financieros a ese respecto.

\section{Artículo 11}

\section{ENTREGA VIGILADA}

1. Si lo permiten los principios fundamentales de sus respectivos ordenamientos jurídicos internos, las Partes adoptarán las medidas necesarias, dentro de sus posibilidades, para que se pueda utilizar de forma adecuada, en el plano internacional, la técnica de entrega vigilada, de conformidad con acuerdos o arreglos mutuamente convenidos, con el fin de descubrir a las personas implicadas en delitos tipificados de conformidad con el párrafo 1 del artículo 3 y de entablar acciones legales contra ellas.

2. Las decisiones de recurrir a la entrega vigilada se adoptarán caso por caso y podrán, cuando sea necesario, tener en cuenta los arreglos financieros y los relativos al ejercicio de su competencia por las Partes interesadas.

3. Las remesas ilícitas cuya entrega vigilada se haya acordado podrán, con el consentimiento de las Partes interesadas, ser interceptadas y autorizadas a proseguir intactas o habiéndose retirado 0 sustituido total o parcialmente los estupefacientes o sustancias sicotrópicas que contengan.

\section{Artículo 12}

\section{SUSTANCIAS QUE SE UTILIZAN CON FRECUENCIA EN LA FABRICACIÓN ILÍCITA DE} ESTUPEFACIENTES O SUSTANCIAS SICOTRÓPICAS

1. Las Partes adoptarán las medidas que estimen adecuadas para evitar la desviación de las sustancias que figuran en el Cuadro I y el Cuadro II, utilizadas en la fabricación ilícita de estupefacientes o sustancias sicotrópicas, y cooperarán entre ellas con este fin.

2. Si una de las Partes o la Junta posee datos que, a su juicio, puedan requerir la inclusión de una sustancia en el Cuadro I o el Cuadro II, lo notificará al Secretario General y le facilitará los datos en que se base la notificación. El procedimiento descrito en los párrafos 2 a 7 del presente artículo también será aplicable cuando una de las Partes o la Junta posea información que justifique suprimir una sustancia del Cuadro I o del Cuadro II o trasladar una sustancia de un Cuadro a otro. 
3. El Secretario General comunicará esa notificación y los datos que considere pertinentes a las Partes, a la Comisión y, cuando la notificación proceda de alguna de las Partes, a la Junta. Las Partes comunicarán al Secretario General sus observaciones acerca de la notificación y toda la información complementaria que pueda serle útil a la Junta para elaborar un dictamen y a la Comisión para adoptar una decisión.

4. Si la Junta, teniendo en cuenta la magnitud, importancia y diversidad del uso lícito de esa sustancia, y la posibilidad y facilidad del empleo de otras sustancias tanto para la utilización lícita como para la fabricación ilícita de estupefacientes o de sustancias sicotrópicas, comprueba:

a) Que la sustancia se emplea con frecuencia en la fabricación ilícita de un estupefaciente o de una sustancia sicotrópica;

b) Que el volumen y la magnitud de la fabricación ilícita de un estupefaciente o de una sustancia sicotrópica crean graves problemas sanitarios o sociales, que justifican la adopción de medidas en el plano internacional, comunicará a la Comisión un dictamen sobre la sustancia, en el que se señale el efecto que tendría su incorporación al Cuadro I o al Cuadro II tanto sobre su uso lícito como sobre su fabricación ilícita, junto con recomendaciones de las medidas de vigilancia que, en su caso, sean adecuadas a la luz de ese dictamen.

5. La Comisión, teniendo en cuenta las observaciones presentadas por las Partes y las observaciones y recomendaciones de la Junta, cuyo dictamen será determinante en cuanto a los aspectos científicos, y tomando también debidamente en consideración otros factores pertinentes, podrá decidir, por una mayoría de dos tercios de sus miembros, incorporar una sustancia al Cuadro I o al Cuadro II.

6. Toda decisión que tome la Comisión de conformidad con el presente artículo será notificada por el Secretario General a todos los Estados y otras entidades que sean Partes en la presente Convención o puedan llegar a serlo y a la Junta. Tal decisión surtirá pleno efecto respecto de cada una de las Partes a los 180 días de la fecha de la notificación.

7. a) Las decisiones de la Comisión adoptadas con arreglo al presente artículo estarán sujetas a revisión por el Consejo, cuando así lo solicite cualquiera de las Partes dentro de un plazo de 180 días contados a partir de la fecha de la notificación de la decisión. La solicitud de revisión será presentada al Secretario General junto con toda la información pertinente en que se base dicha solicitud de revisión.

b) El Secretario General transmitirá copias de la solicitud de revisión y de la información pertinente a la Comisión, a la Junta y a todas las Partes, invitándolas a presentar sus observaciones dentro del plazo de 90 días. Todas las observaciones que se reciban se comunicarán al Consejo para que éste las examine.

c) El Consejo podrá confirmar o revocar la decisión de la Comisión. La notificación de la decisión del Consejo se transmitirá a todos los Estados y otras entidades que sean Partes en la presente Convención o que puedan Ilegar a serlo, a la Comisión y a la Junta.

8. a) Sin perjuicio de las disposiciones de carácter general del párrafo 1 del presente artículo y de lo dispuesto en la Convención de 1961, en la Convención de 1961 en su forma enmendada y en el Convenio de 1971, las Partes tomarán las medidas que estimen oportunas para vigilar la fabricación y la distribución de sustancias que figuren en los Cuadros I y II que se realicen dentro de su territorio.

b) Con este fin las Partes podrán:

i) Controlar a todas las personas y empresas que se dediquen a la fabricación o la distribución de tales sustancias;

ii) Controlar bajo licencia el establecimiento y los locales en que se realicen las mencionadas fabricación o distribución;

iii) Exigir que los licenciatarios obtengan la autorización para realizar las mencionadas operaciones;

iv) Impedir la acumulación en posesión de fabricantes y distribuidores de cantidades de esas sustancias que excedan de las que requieran el desempeño normal de las actividades comerciales y las condiciones prevalecientes en el mercado.

9. Cada una de las Partes adoptará, con respecto a las sustancias que figuren en el Cuadro I y el Cuadro II, las siguientes medidas:

a) Establecer y mantener un sistema para vigilar el comercio internacional de sustancias que figuran en el Cuadro I y el Cuadro II a fin de facilitar el descubrimiento de operaciones sospechosas. Esos sistemas de vigilancia deberán aplicarse en estrecha cooperación con los 
fabricantes, importadores, exportadores, mayoristas y minoristas, que deberán informar a las autoridades competentes sobre los pedidos y operaciones sospechosos;

b) Disponer la incautación de cualquier sustancia que figure en el Cuadro I o el Cuadro II si hay pruebas suficientes de que se ha de utilizar para la fabricación ilícita de estupefacientes o sustancias sicotrópicas;

c) Notificar, lo antes posible, a las autoridades y servicios competentes de las Partes interesadas si hay razones para presumir que la importación, la exportación o el tránsito de una sustancia que figura en el Cuadro I o el Cuadro II se destina a la fabricación ilícita de estupefacientes o sustancias sicotrópicas, facilitando, en particular, información sobre los medios de pago y cualesquiera otros elementos esenciales en los que se funde esa presunción;

d) Exigir que las importaciones y exportaciones estén correctamente etiquetadas y documentadas. Los documentos comerciales como facturas, manifiestos de carga, documentos aduaneros y de transporte y otros documentos relativos al envío, deberán contener los nombres, tal como figuran en el Cuadro I o el Cuadro II, de las sustancias que se importen o exporten, la cantidad que se importe o exporte y el nombre y la dirección del importador, del exportador y, cuando sea posible, del consignatario;

e) Velar porque los documentos mencionados en el inciso d) sean conservados durante dos años por lo menos y puedan ser inspeccionados por las autoridades competentes.

10. a) Además de lo dispuesto en el párrafo 9, y a petición de la Parte interesada dirigida al Secretario General, cada una de las Partes de cuyo territorio se vaya a exportar una de las sustancias que figuran en el Cuadro I velará porque, antes de la exportación, sus autoridades competentes proporcionen la siguiente información a las autoridades competentes del país importador:

i) El nombre y la dirección del exportador y del importador y, cuando sea posible, del consignatario;

ii) El nombre de la sustancia que figura en el Cuadro I;

iii) La cantidad de la sustancia que se ha de exportar;

iv) El punto de entrada y la fecha de envío previstos;

v) Cualquier otra información que acuerden mutuamente las Partes.

b) Las Partes podrán adoptar medidas de fiscalización más estrictas o rigurosas que las previstas en el presente párrafo si, a su juicio, tales medidas son convenientes o necesarias.

11. Cuando una de las Partes facilite información a otra Parte con arreglo a lo dispuesto en los párrafos 9 y 10 del presente artículo, la Parte que facilita tal información podrá exigir que la Parte que la reciba respete el carácter confidencial de los secretos industriales, empresariales, comerciales o profesionales o de los procesos industriales que contenga.

12. Cada una de las Partes presentará anualmente a la Junta, en la forma y de la manera que ésta disponga y en los formularios que ésta suministre, información sobre:

a) Las cantidades incautadas de sustancias que figuran en el Cuadro I y el Cuadro II y, cuando se conozca, su origen;

b) Cualquier sustancia que no figure en el Cuadro I o el Cuadro II, pero de la que se sepa que se emplea en la fabricación ilícita de estupefacientes o sustancias sicotrópicas y que, a juicio de esa Parte, sea considerada lo bastante importante para ser señalada a la atención de la Junta;

c) Los métodos de desviación y de fabricación ilícita.

13. La Junta informará anualmente a la Comisión sobre la aplicación del presente artículo, y la Comisión examinará periódicamente la idoneidad y la pertinencia del Cuadro I y del Cuadro II.

14. Las disposiciones del presente artículo no se aplicarán a los preparados farmacéuticos ni a otros preparados que contengan sustancias que figuran en el Cuadro I o el Cuadro II y que estén compuestos de forma tal que esas sustancias no puedan emplearse o recuperarse fácilmente por medios de sencilla aplicación. 
Las Partes adoptarán las medidas que consideren adecuadas para impedir el comercio y la desviación de materiales y equipos destinados a la producción o fabricación ilícitas de estupefacientes y sustancias sicotrópicas y cooperarán a este fin.

\section{Artículo 14}

MEDIDAS PARA ERRADICAR EL CULTIVO ILÍCITO DE PLANTAS DE LAS QUE SE EXTRAEN ESTUPEFACIENTES Y PARA ELIMINAR LA DEMANDA ILÍCITA DE ESTUPEFACIENTES Y SUSTANCIAS SICOTRÓPICAS

1. Cualquier medida adoptada por las Partes para la aplicación de la presente Convención no será menos estricta que las normas aplicables a la erradicación del cultivo ilícito de plantas que contengan estupefacientes y sustancias sicotrópicas y a la eliminación de la demanda ilícita de estupefacientes y sustancias sicotrópicas conforme a lo dispuesto en la Convención de 1961, en la Convención de 1961 en su forma enmendada y en el Convenio de 1971.

2. Cada una de las Partes adoptará medidas adecuadas para evitar el cultivo ilícito de las plantas que contengan estupefacientes o sustancias sicotrópicas, tales como las plantas de adormidera, los arbustos de coca y las plantas de cannabis, así como para erradicar aquellas que se cultiven ilícitamente en su territorio. Las medidas que se adopten deberán respetar los derechos humanos fundamentales y tendrán debidamente en cuenta los usos tradicionales lícitos, donde al respecto exista la evidencia histórica, así como la protección del medio ambiente.

3. a) Las Partes podrán cooperar para aumentar la eficacia de los esfuerzos de erradicación. Tal cooperación podrá comprender, entre otras cosas, el apoyo, cuando proceda, al desarrollo rural integrado tendiente a ofrecer soluciones sustitutivas del cultivo ilícito que sean económicamente viables. Factores como el acceso a los mercados, la disponibilidad de recursos y las condiciones socioeconómicas imperantes deberán ser tomados en cuenta antes de que estos programas hayan sido puestos en marcha. Las Partes podrán llegar a acuerdos sobre cualesquiera otras medidas adecuadas de cooperación.

b) Las Partes facilitarán también el intercambio de información científicas y técnica y la realización de investigaciones relativas a la erradicación.

c) Cuando tengan fronteras comunes, las Partes tratarán de cooperar en programas de erradicación en sus respectivas zonas situadas a lo largo de dichas fronteras.

4. Las Partes adoptarán medidas adecuadas tendientes a eliminar o reducir la demanda ilícita de estupefacientes y sustancias sicotrópicas con miras a reducir el sufrimiento humano y acabar con los incentivos financieros del tráfico ilícito. Estas medidas podrán basarse, entre otras cosas, en las recomendaciones de las Naciones Unidas, los organismos especializados de las Naciones Unidas, tales como la Organización Mundial de la Salud, y otras organizaciones internacionales competentes, y en el Plan Amplio y Multidisciplinario aprobado por la Conferencia internacional sobre el Uso Indebido y el Tráfico Ilícitos de Drogas celebrada en 1987, en la medida en que éste se relacione con los esfuerzos de las organizaciones gubernamentales y no gubernamentales y de entidades privadas en las esferas de la prevención, del tratamiento y de la rehabilitación. Las Partes podrán concertar acuerdos o arreglos bilaterales o multilaterales tendientes a eliminar o reducir la demanda ilícita de estupefacientes y sustancias sicotrópicas.

5. Las Partes podrán asimismo adoptar las medidas necesarias para que los estupefacientes, sustancias sicotrópicas y sustancias que figuran en el Cuadro I y el Cuadro II que se hayan incautado o decomisado sean destruidas prontamente o se disponga de ellas de acuerdo con la ley y para que las cantidades necesarias debidamente certificadas de esas sustancias sean admisibles a efectos probatorios.

\section{Artículo 15}

\section{TRANSPORTISTAS COMERCIALES}

1. Las Partes adoptarán medidas adecuadas a fin de garantizar que los medios de transporte utilizados por los transportistas comerciales no lo sean para cometer delitos tipificados de conformidad con el párrafo I del artículo 3; entre esas medidas podrá figurar la concertación de arreglos especiales con los transportistas comerciales. 
2. Cada una de las Partes exigirá a los transportistas comerciales que tomen precauciones razonables a fin de impedir que sus medios de transporte sean utilizados para cometer delitos tipificados de conformidad con el párrafo 1 del artículo 3. Entre esas precauciones podrán figurar las siguientes:

a) Cuando el establecimiento principal del transportista comercial se encuentre en el territorio de dicha Parte:

i) La capacitación del personal para descubrir personas o remesas sospechosas;

ii) El estímulo de la integridad moral del personal.

b) Cuando el transportista comercial desarrolle actividades en el territorio de dicha Parte:

i) La presentación por adelantado, cuando sea posible, de los manifiestos de carga;

ii) La utilización en los contenedores de sellos inviolables y verificables individualmente;

iii) La denuncia a las autoridades competentes, en la primera ocasión, de cualquier circunstancia sospechosa que pueda estar relacionada con la comisión de delitos tipificados de conformidad con el párrafo 1 del artículo 3.

3. Cada una de las Partes procurará garantizar que los transportistas comerciales y las autoridades competentes de los lugares de entrada y salida, y demás zonas de control aduanero, cooperen a fin de impedir el acceso no autorizado a los medios de transporte y a la carga, así como en la aplicación de las medidas de seguridad adecuadas.

\section{Artículo 16}

\section{DOCUMENTOS COMERCIALES Y ETIQUETAS DE LAS EXPORTACIONES}

1. Cada una de las Partes exigirá que las exportaciones licitas de estupefacientes y sustancias sicotrópicas estén debidamente documentadas. Además de los requisitos de documentación previstos en el artículo 31 de la Convención de 1961, en el artículo 31 de la Convención de 1961 en su forma enmendada y en el artículo 12 del Convenio de 1971, en los documentos comerciales, tales como facturas, manifiestos de carga, documentos aduaneros y de transporte y otros documentos relativos al envío, deberán indicarse los nombres de los estupefacientes y sustancias sicotrópicas que se exporten, tal como figuren en las Listas correspondientes de la Convención de 1961, de la Convención de 1961 en su forma enmendada y del Convenio de 1971, así como la cantidad exportada y el nombre y la dirección del exportador, del importador y, cuando sea posible, del consignatario.

2. Cada una de las Partes exigirá que las remesas de estupefacientes y sustancias Sicotrópicas exportadas no vayan incorrectamente etiquetadas.

\section{Artículo 17}

\section{TRÁFICO ILÍCITO POR MAR}

1. Las Partes cooperarán en todo lo posible para eliminar el tráfico ilícito por mar, de conformidad con el derecho internacional del mar.

2. Toda Parte que tenga motivos razonables para sospechar que una nave de su pabellón, o que no enarbole ninguno o no lleve matrícula, está siendo utilizada para el tráfico ilícito, podrá solicitar asistencia de otras Partes a fin de poner termino a esa utilización. Las Partes a las que se solicite dicha asistencia la prestarán con los medios de que dispongan.

3. Toda Parte que tenga motivos razonables para sospechar que una nave que esté haciendo uso de la libertad de navegación con arreglo al derecho internacional y que enarbole el pabellón o lleve matrícula de otra Parte, esta siendo utilizada para el tráfico ilícito, podrá notificarlo al Estado del pabellón y pedir que confirme la matrícula; si la confirma, podrá solicitarle autorización para adoptar las medidas adecuadas con respecto a esa nave. 
4. De conformidad con el párrafo 3 o con los tratados vigentes entre las Partes, o con cualquier otro acuerdo o arreglo que se haya podido concertar entre ellas, el Estado del pabellón podrá autorizar al Estado requirente, entre otras cocas, a:
a) Abordar la nave;
b) Inspeccionar la nave;
c) Si se descubren pruebas de implicación en el tráfico ilícito, adoptar medidas adecuadas
con respecto a la nave, a las personas y a la carga que se encuentren a bordo.

5. Cuando se adopte una medida de conformidad con el presente artículo, las Partes interesadas tendrán debidamente en cuenta la necesidad de no poner en peligro la seguridad de la vida en el mar ni la de la nave y la carga y de no perjudicar los intereses comerciales y jurídicos del Estado del pabellón o de cualquier otro Estado interesado.

6. El Estado del pabellón podrá, en consonancia con sus obligaciones previstas en el párrafo 1 del presente artículo, someter su autorización a condiciones que serán convenidas entre dicho Estado y la Parte requirente, sobre todo en lo que concierne a la responsabilidad.

7. A los efectos de los párrafos 3 y 4 del presente artículo, las Partes responderán con celeridad a las solicitudes de otras Partes de que se averigüe si una nave que esté enarbolando su pabellón está autorizada a hacerlo, así como a las solicitudes de autorización que se presenten a tenor de lo previsto en el párrafo 3. Cada Estado, en el momento de entrar a ser Parte en la presente Convención, designará una 0 , en caso necesario, varias autoridades para que se encarguen de recibir dichas solicitudes y de responder a ellas. Esa designación será dada a conocer, por conducto del Secretario General, a todas las demás Partes, dentro del mes siguiente a la designación.

8. La Parte que haya adoptado cualquiera de las medidas previstas en el presente artículo informará con prontitud al Estado del pabellón de los resultados de esa medida.

9. Las Partes considerarán la posibilidad de concertar acuerdos o arreglos bilaterales y regionales para llevar a la práctica las disposiciones del presente artículo o hacerlas más eficaces.

10. Las medidas que se adopten en cumplimiento del párrafo 4 del presente artículo serán sólo aplicadas por buques de guerra o aeronaves militares, u otras naves o aeronaves que lleven signos claros y sean identificables como naves o aeronaves al servicio de un gobierno y autorizadas a tal fin.

11. Toda medida adoptada de conformidad con el presente artículo tendrá debidamente en cuenta la necesidad de no interferir en los derechos y obligaciones de los Estados ribereños o en el ejercicio de su competencia, que sean conformes con el derecho internacional del mar, ni de menoscabar esos derechos, obligaciones o competencias.

\section{Artículo 18}

\section{ZONAS Y PUERTOS FRANCOS}

1. Las Partes, a fin de eliminar, en las zonas y puertos francos, el tráfico ilícito de estupefacientes, sustancias sicotrópicas y sustancias que figuran en los Cuadros I y II adoptarán medidas no menos estrictas que las que apliquen en otras partes de su territorio.

2. Las Partes procurarán:

a) Vigilar el movimiento de bienes y personas en las zonas y puertos francos, a cuyo fin facultarán a las autorizadas competentes a inspeccionar las cargas y las naves a su llegada y partida, incluidas las embarcaciones de recreo y los barcos pequeños, así como las aeronaves y los vehículos y, cuando proceda, a registrar a los miembros de la tripulación y los pasajeros, así como los equipajes respectivos;

b) Establecer y mantener un sistema para descubrir los envíos sospechosos de contener estupefacientes, sustancias sicotrópicas y sustancias que figuran en los Cuadros I y II que entren en dichas zonas o salgan de ellas;

c) Establecer y mantener sistemas de vigilancia en las zonas del puerto y de los muelles, en los aeropuertos y en los puestos de control fronterizo de las zonas y puertos francos. 


\section{UTILIZACIÓN DE LOS SERVICIOS POSTALES}

1. Las Partes, de conformidad con las obligaciones que les incumben en virtud de las Convenciones de la Unión Postal Universal, y de acuerdo con los principios fundamentales de sus respectivos ordenamientos jurídicos internos, adoptarán medidas a fin de suprimir la utilización de los servicios postales para el tráfico ilícito y cooperarán con ese propósito.

2. Las medidas a que se refiere el párrafo 1 del presente artículo comprenderán, en particular:

a) Medidas coordinadas y orientadas a prevenir y reprimir la utilización de los servicios postales para el tráfico ilícito;

b) La introducción y el mantenimiento, por el personal de detección y represión competente, de técnicas de investigación y de control encaminadas a detectar los envíos postales con remesas ilícitas de estupefacientes, sustancias sicotrópicas y sustancias que figuran en los Cuadros I y II;

c) Medidas legislativas que permitan utilizar los medios adecuados a fin de allegar las pruebas necesarias para iniciar actuaciones judiciales.

\section{Artículo 20}

\section{INFORMACIÓN QUE DEBEN SUMINISTRAR LAS PARTES}

I. Las Partes suministrarán, por mediación del Secretario General, información a la Comisión sobre el funcionamiento de la presente Convención en sus territorios, y, en particular:

a) El texto de las leyes y reglamentos que promulguen para dar efecto a la Convención:

b) Los pormenores de casos de tráfico ilícito dentro de su jurisdicción que estimen importantes por las nuevas tendencias que revelen, las cantidades de que se trate, las fuentes de procedencia de las sustancias o los métodos utilizados por las personas que se dedican al tráfico ilícito.

2. Las Partes facilitarán dicha información del modo y en la fecha que solicite la Comisión.

\section{Artículo 21}

\section{FUNCIONES DE LA COMISIÓN}

La Comisión tendrá autoridad para estudiar todas las cuestiones relacionadas con los objetivos de la presente Convención, y, en particular:

a) La Comisión examinará el funcionamiento de la presente Convención, sobre la base de la información presentada por las Partes de conformidad con el artículo 20;

b) La Comisión podrá hacer sugerencias y recomendaciones de carácter general basadas en el examen de la información recibida de las Partes;

c) La Comisión podrá señalar a la atención de la Junta cualquier cuestión que tenga relación con las funciones de la misma;

d) La Comisión tomará las medidas que estime adecuadas sobre cualquier cuestión que le haya remitido la Junta de conformidad con el inciso b) del párrafo 1 del artículo 22;

e) La Comisión, con arreglo al procedimiento establecido en el artículo 12, podrá enmendar el Cuadro I y el Cuadro II;

f) La Comisión podrá señalar a la atención de los Estados no Partes las decisiones y recomendaciones que adopte en cumplimiento de la presente Convención, a fin de que dichos Estados examinen la posibilidad de tomar medidas de acuerdo con tales decisiones y recomendaciones. 
1. Sin perjuicio de las funciones de la Comisión previstas en el artículo 21 y sin perjuicio de las funciones de la Junta y de la Comisión previstas en la Convención de 1961, en la Convención de 1961 en su forma enmendada y en el Convenio de 1971:

a) Si, sobre la base de su examen de la información a disposición de ella, del Secretario General o de la Comisión, o de la información comunicada por órganos de las Naciones Unidas, la Junta tiene motivos para creer que no se cumplen los objetivos de la presente Convención en asuntos de su competencia, la Junta podrá invitar a una o mas Partes a suministrar toda información pertinente;

b) Con respecto a los artículos 12,13 y 16 :

i) Una vez cumplido el trámite señalado en el inciso a) del presente artículo; la Junta podrá, si lo juzga necesario, pedir a la Parte interesada que adopte las medidas correctivas que las circunstancias aconsejen para el cumplimiento de lo dispuesto en los artículos 12, 13 y 16:

ii) Antes de tomar ninguna medida conforme al apartado iii) infra, la Junta tratará confidencialmente sus comunicaciones con la Parte interesada conforme a los incisos anteriores;

iii) Si la Junta considera que la Parte interesada no ha adoptado las medidas correctivas que se le han pedido conforme a este inciso, podrá señalar el asunto a la atención de las Partes, del Consejo y de la Comisión. Cualquier informe que publique la Junta de conformidad con este inciso incluirá asimismo las opiniones de la Parte interesada si ésta así lo solicitare.

2. Se invitará a toda Parte interesada a que esté representada en las reuniones de la Junta en las que se haya de examinar de conformidad con el presente artículo una cuestión que le afecte directamente.

3. Si, en algún caso, una decisión de la Junta que se adopte de conformidad con el presente artículo no fuese unánime, se dejará constancia de las opiniones de la minoría.

4. Las decisiones de la Junta de conformidad con el presente artículo se tomarán por mayoría de dos tercios del numero total de miembros de la Junta.

5. En el desempeño de sus funciones de conformidad con el inciso a) del párrafo 1 del presente artículo, la Junta protegerá el carácter confidencial de toda información que llegue a su poder.

6. La responsabilidad de la Junta en virtud del presente artículo no se aplicará al cumplimiento de tratados o acuerdos celebrados entre las Partes de conformidad con lo dispuesto en la presente Convención.

7. Lo dispuesto en el presente artículo no será aplicable a las controversias entre las Partes a las que se refieren las disposiciones del artículo 32.

\section{Artículo 23}

INFORMES DE LA JUNTA

1. La Junta preparará un informe anual sobre su labor en el que figure un análisis de la información de que disponga y, en los casos adecuados, una relación de las explicaciones, si las hubo, dadas por las Partes o solicitadas a ellas, junto con cualesquiera observaciones y recomendaciones que la Junta desee formular. La Junta podrá preparar los informes adicionales que considere necesarios. Los informes serán presentados al Consejo por conducto de la Comisión, la cual podrá hacer las observaciones que juzgue convenientes.

2. Los informes de la junta serán comunicados a las Partes y posteriormente publicados por el Secretario General. Las Partes permitirán la distribución sin restricciones de dichos informes. 
Las Partes podrán adoptar medidas más estrictas o rigurosas que las previstas en la presente Convención si, a su juicio, tales medidas son convenientes o necesarias para prevenir o eliminar el tráfico ilícito.

\section{Artículo 25}

\section{EFECTO NO DEROGATORIO RESPECTO DE ANTERIORES DERECHOS Y OBLIGACIONES CONVENCIONALES}

Las disposiciones de la presente Convención serán sin perjuicio de los derechos y obligaciones que incumben a las Partes en la presente Convención en virtud de la Convención de 1961, de la Convención de 1961 en su forma enmendada y del Convenio de 1971.

\section{Artículo 26 \\ FIRMA}

La presente Convención estará abierta desde el 20 de diciembre de 1988 hasta el 28 de febrero de 1989 en la Oficina de las Naciones Unidas en Viena y, después, hasta el 20 de diciembre de 1989 en la Sede de las Naciones Unidas en Nueva York, a la firma:
a) De todos los Estados;
b) De Namibia, representada por el Consejo de las Naciones Unidas para Namibia;
c) De las organizaciones regionales de integración económica que sean competentes para negociar, concertar y aplicar acuerdos internacionales sobre cuestiones reguladas en la presente Convención, siendo aplicables a dichas organizaciones dentro de los límites de su competencia las referencias que en la presente Convención se hagan a las Partes, los Estados o los servicios nacionales.

\section{Artículo 27}

RATIFICACIÓN, ACEPTACIÓN, APROBACIÓN O ACTO DE CONFIRMACIÓN FORMAL

1. La presente Convención estará sujeta a ratificación, aceptación o aprobación por los Estados y por Namibia, representada por el Consejo de las Naciones Unidas para Namibia, y a los actos de confirmación formal por las organizaciones regionales de integración económica a las que se hace referencia en el inciso c) del artículo 26. Los instrumentos de ratificación, aceptación o aprobación y los instrumentos relativos a los actos de confirmación formal serán depositados ante el Secretario General.

2. En sus instrumentos de confirmación formal, las organizaciones regionales de integración económica declararán el alcance de su competencia con respecto a las cuestiones regidas por la presente Convención. Esas organizaciones comunicarán también al Secretario General cualquier modificación del alcance de su competencia con respecto a las cuestiones regidas por la presente Convención.

\section{Artículo 28}

\section{ADHESIÓN}

1. La presente Convención quedará abierta a la adhesión de todo Estado, de Namibia, representada por el Consejo de las Naciones Unidas para Namibia, y de las organizaciones regionales de integración económica a las que se hace referencia en el inciso c) del artículo 26. La adhesión se efectuará mediante el depósito de un instrumento de adhesión ante el Secretario General.

2. En sus instrumentos de adhesión, las organizaciones regionales de integración económica declararán el alcance de su competencia con respecto a las cuestiones regidas por la presente Convención. Estas organizaciones comunicarán también al Secretario General cualquier modificación del alcance de su competencia con respecto a las cuestiones regidas por la presente Convención. 


\section{ENTRADA EN VIGOR}

1. La presente Convención entrará en vigor el nonagésimo día siguiente a la fecha en que haya sido depositado ante el Secretario General el vigésimo instrumento de ratificación, aceptación, aprobación o adhesión por los Estados o por Namibia, representada por el Consejo de las Naciones Unidas para Namibia.

2. Para cada Estado o para Namibia, representada por el Consejo de las Naciones Unidas para Namibia, que ratifique, acepte o apruebe la presente Convención o se adhiera a ella después de haberse depositado el vigésimo instrumento de ratificación, de aceptación, de aprobación o de adhesión, la presente Convención entrará en vigor el nonagésimo día siguiente a la fecha en que tal Estado o Namibia haya depositado dicho instrumento de ratificación, de aceptación, de aprobación o de adhesión.

3. Para cada organización regional de integración económica a la que se hace referencia en el inciso c) del artículo 26, que deposite un instrumento relativo a un acto de confirmación formal o un instrumento de adhesión, la presente Convención entrará en vigor el nonagésimo día siguiente a la fecha en que, se haya efectuado ese deposito, o en la fecha en que la presente Convención entre en vigor conforme al párrafo I del presente artículo, si esta última es posterior.

\section{Artículo 30}

\section{DENUNCIA}

1. Cada una de las Partes podrá en cualquier momento denunciar la presente Convención mediante notificación escrita dirigida al Secretario General.

2. La denuncia surtirá efecto para la Parte interesada un año después de la fecha en que la notificación haya sido recibida por el Secretario General.

\section{Artículo 31}

\section{ENMIENDAS}

1. Cualquiera de las Partes podrá proponer una enmienda a la presente Convención. Dicha Parte comunicará el texto de cualquier enmienda así propuesta y los motivos de la misma al Secretario General, quien, a su vez, comunicará la enmienda propuesta a las demás Partes y les preguntará si la aceptan. En el caso de que la propuesta de enmienda así distribuida no haya sido rechazada por ninguna de las Partes dentro de los veinticuatro meses siguientes a su distribución, se considerará que la enmienda ha sido aceptada y entrará en vigor respecto de cada una de las Partes noventa días después de que esa Parte haya depositado ante el Secretario General un instrumento en el que exprese su consentimiento a quedar obligada por esa enmienda.

2. Cuando una propuesta de enmienda haya sido rechazada por alguna de las Partes, el Secretario General consultará con las Partes y, si la mayoría de ellas lo solicita, someterá la cuestión, junto con cualquier observación que haya sido formulada por las Partes, a la consideración del Consejo, el cual podrá decidir convocar una conferencia de conformidad con el párrafo 4 del Artículo 62 de la Carta de las Naciones Unidas. Las enmiendas que resulten de esa Conferencia serán incorporadas en un Protocolo de Modificación. El consentimiento en quedar vinculada por dicho Protocolo deberá ser notificado expresamente al Secretario General.

\section{Artículo 32}

\section{SOLUCIÓN DE CONTROVERSIAS}

1. En caso de controversia acerca de la interpretación o de la aplicación de la presente Convención entre dos o mas Partes, éstas se consultarán con el fin de resolverla por vía de negociación, investigación, mediación, conciliación, arbitraje, recurso a organismos regionales, procedimiento judicial u otros medios pacíficos de su elección. 
2. Toda controversia de esta índole que no haya sido resuelta en la forma prescrita en el párrafo 1 del presente artículo será sometida, a petición de cualquiera de los Estados Partes en la controversia, a la decisión de la Corte Internacional de Justicia.

3. Si una de las organizaciones regionales de integración económica, a las que se hace referencia en el inciso c) del artículo 26, es Parte en una controversia que no haya sido resuelta en la forma prescrita en el párrafo 1 del presente artículo, podrá, por conducto de un Estado Miembro de las Naciones Unidas, pedir al Consejo que solicite una opinión consultiva a la Corte Internacional de Justicia de conformidad con el artículo 65 del Estatuto de la Corte, opinión que se considerará decisiva.

4. Todo Estado, en el momento de la firma o la ratificación, la aceptación o la aprobación de la presente Convención o de su adhesión a la misma, o cada organización regional de integración económica en el momento de la firma o el depósito de un acto de confirmación formal o de la adhesión, podrá declarar que no se considera obligado por los párrafos 2 y 3 del presente artículo. Las demás Partes no estarán obligadas por los párrafos 2 y 3 del presente artículo ante ninguna Parte que haya hecho dicha declaración.

5. Toda Parte que haya hecho la declaración prevista en el párrafo 4 del presente artículo podrá retirarla en cualquier momento notificándolo al Secretario General.

Artículo 33

TEXTOS AUTÉNTICOS

Los textos en árabe, chino, español, francés, inglés y ruso de la presente Convención son igualmente auténticos.

\section{Artículo 34}

DEPOSITARIO

El Secretario General será el depositario de la presente Convención.

EN TESTIMONIO DE LO CUAL, los abajo firmantes, debidamente autorizados para ello, han firmado la presente Convención.

HECHA EN VIENA, en un solo original, el día veinte de diciembre de mil novecientos ochenta y ocho. 